\title{
VIRTUAL ENVIRONMENT FOR DIAGNOSING DysleXic CHILdREN’ Visual SPATIAL Potential
}

\author{
Jamilah Hamid, Nor Hasbiah Ubaidullah and Aslina Saad \\ Department of Computing, Faculty of Art, Computing \& Creative Industry, Sultan Idris \\ Education University, Tg Malim, Perak, Malaysia
}

\begin{abstract}
This paper discusses the design of a non-immersive virtual environment for diagnosing dyslexic children's visual-spatial potential called D-Potensi and the diagnostic testing of the prototype. The design of the virtual environment is based on the adaption of Sutcliffe's VR development methodology, comprising four activities: (i) determining type of VR, (ii) selecting modalities and interaction devices, (iii) creating and modelling $3 D$ objects, and (iv)creating terrains. For the diagnostic testing, a qualitative approach using semi-structured interview and an observation technique were used to identify the potential problems of DPotensi. Participants of the diagnostic test comprised the president of Malaysian Dyslexia Association (MDA), a dyslexic teacher, the father of a dyslexic child, and five dyslexic children. The results of the test suggest that the design of D-Potensi virtual environment needs further improvement to enhance its usability. As such, the researchers propose a number of suggestions to improve the design of D-Potensi virtual environment.
\end{abstract}

\section{KEYWORDS}

Goal-directed exploration, web-based virtual environment, non-immersive VR, dyslexic children's visualspatial potential

\section{INTRODUCTION}

The statistics released by the International Telecommunication Union (ITU) show that there has been a dramatic increase in worldwide Internet use, indicating that about 47 per cent of the world's population are using the Internet in 2016 compared to a mere one per cent before 1995 [1]. Such an increase might be due to the various types of Internet use, which had originally served as an information-sharing site but has now turned into a one-stop center for various activities, such as education, training, commerce, and entertainment, spurred by the social media. Of late, according to Mennecke et al., virtual reality (VR) Internet applications have become popular among users [2]. However, studies of related literature have shown that most web-based VR applications are largely focused on normal individuals only[3-7]. In fact, web-based VR applications for people with disabilities are limited, despite efforts of various parties to help such users to gain greater access to such VR sites [8,9]. In this regard, UNESCO has included disabled and dyslexic individuals as individuals with learning disabilities [8]. The number of dyslexics, including those exhibiting dyslexic symptoms, is increasingly growing, topping $15-20 \%$ of the world population [10].

Given this sizable number of such individuals, many web-based applications have been developed to cater to their needs. Generally, a majority of the web applications are used for reading remedy and diagnosis of dyslexic symptoms of such individuals, and only a handful are dedicated to help determine the potentials or talents of dyslexics. Such a lack of dedicated

DOI: $10.5121 /$ ijma.2017.9609 
The International Journal of Multimedia \& Its Applications (IJMA) Vol.9, No.4/5/6, December 2017

applications is regrettable, given that many researchers agree that dyslexic individuals have unique visual-spatial (VS) skill that needs to be recognized so that they can lead a better life [1118]. Furthermore, a group of researchers has highlighted that the process of diagnosing dyslexic children' potentials or skills in their early childhood is important to ensure their innate talents can identified and nurtured, which can then be tailored to appropriate courses or programs to help maximize their learning [11,19, 20- 22].

Currently, most websites that offer psychometric or aptitude testing only focus on general users and use a two-dimensional (2D) approach, which may not suitable for the assessment of specific abilities such as VS skill. Arguably, the 2D approach is not only ineffective but also inaccurate due to its inherent limitations such as less interactivity and diversity of functions. Thus, several researcher have suggested the use of the VR approach in the development of psychometric testing tools [23-25]. For example, Cohen and Hegarty [23] strongly recommended the use of the VR approach in web-based psychometric testing tools for children. In fact, a few researchers [26, 27] emphasized the needs for dedicated websites for children with dyslexia as nearly $33 \%$ of internet users are dyslexic individuals, including those exhibiting mild dyslexia. According to these researchers, the problems most often encountered by such users when browsing the internet are due to the following factors: (i) misleading display layout, (ii) unclear navigation, (iii) inappropriate color selection, (iv) graphs and texts that are too small, and (v) use of complex language. As such, from the navigation aspect, VR websites need to focus not only on navigation between pages but also on exploration in a virtual environment. For the exploration elements, Sutcliffe [28] proposed specific guidelines for two types of exploration application, namely goal directed exploration application and navigation exploration application. For legibility and readability of text for dyslexic people, Smythe and Draffan [29] recommended several criteria for website development, such as typeface, font size, spacing, and color of text, background, and scrolling. Thus, the design and development of VR websites for dyslexic children needs to focus on all these elements such that they can surf the websites with greater ease.

Premised on the above background, this study was carried out with the main aim to develop a VR prototype of a Web-based Non-immersive Virtual Environment Application, called D-Potensi, to help diagnose virtual-spatial potential among dyslexic children. This paper consists of two parts, with the first part elaborating the design of D-Potensi and the second discussing the diagnostic testing of D-Potensi prototype.

\section{Designing Virtual Environment Of D-Potensi}

Clearly, VR applications development is more complex compared to the development of 2D or 3D multimedia applications. This is because VR applications have unique features, such as realism, latency, physical factor, frame rate per second and others, with which developers have to deal. After reviewing several specific methodologies for VR development, the researcher chose the VR development methodology proposed by Sutcliffe [28]. Specifically, the goal directed exploration guideline was used in the development of D-Potensi such as to help motivate such children in performing several given tasks. This methodology consists of five (5) phases as follows: (i) requirement analysis, (ii) task and domain analysis, (iii) virtual environment design, (iv) prototype development, and (v) evaluation. However, for this paper, only the third phase of the methodology for the virtual environment design is discussed. The design phase of the virtual environment consists of four activities as follows: (i) determining the type of VR, (ii) selecting modalities and interaction devices, (iii) creating and modeling 3D objects, and (iv) creating terrain. 
The International Journal of Multimedia \& Its Applications (IJMA) Vol.9, No.4/5/6, December 2017

\subsection{DETERMINING THE TYPE OF VR}

Currently, there are various VR definitions and VR classifications. As such, to avoid confusion of such terminologies, several researchers have proposed three (3) VR categories based on the immersive level of such applications as follows: (i) immersive VR applications, (ii) semiimmersive VR applications, and (iii) non-immersive VR applications. Such categorization can certainly help facilitate the development of a specific VR application [30]. Among the three types of VR applications, non-immersive (desktop) VR applications are the most affordable and practical, as such applications can be readily implemented using a set of desktops as opposed to immersive and semi-immersive VR applications that require expensive special equipment, such as screen stereoscopes, head-mounted displays, special glove, and a cave (specific place for the environment). Obviously, this specialized equipment is not only prohibitively expensive but also difficult to acquire and use. In fact, using such hardware entails detailed planning and training to suit individual users' needs, which naturally incurs high cost. Such concern is best exemplified by Gosselin and Andriot's [31] assertion that in designing a haptic device, developers need to take into account many important elements, such as positioning, grip type, static capacity, and type of force that is appropriate for the user, which complicates the implementation of web-based VR applications.

Apart from cost and equipment constraint, users' capabilities must be taken into consideration as well, as the operation of a VR application is different from those of other computer applications. For instance, in immersive and semi immersive VR applications, the view, position, and movement of the user' body are important for immersive experience in a virtual world. According to Coquillart, Fuchs, Grosjean and Hachet [32], physical movements in the virtual world can be complex due to several factors, such as gravity, speed, virtual space, and technique used. As such, Reis, Duarte and Rebelo [33] assert that features that can immerse and engage user should be carefully considered in the development of VR applications. Without careful considerations of such features, users can inevitably experience discomfort, disorientation, and cyber sickness, especially in navigating and exploring immersive virtual environments using cumbersome specialized equipment or hardware [34-36]. In contrast, according to Polcar and Horejsi [37], such problems are virtually eliminated with the use of non-immersive VR applications.

Hence, in view of the potential problems highlighted above, the researchers chose non-immersive (desktop) VR technology for the development of D-Potensi. This novel application was implemented on the desktop platform, enabling children with dyslexia to diagnose the VS potential more readily. Admittedly, the aspect of realism of non-immersive VR applications is less than that of the immersive and semi-immersive VR applications; however, some studies [37, 38] have found that the former technology was equally effective in helping users to achieve the objectives of certain tasks in the non-immersive environment.

\subsection{Selecting Modalities ANd INTERACTION DEVICES}

The modalities for human-computer interaction in immersive environment are mainly visual, audio, haptic, motor, and olfaction [28]. Given that D-Potensi is a non-immersive VR application, the main input devices used for this application consisted of a keyboard and a mouse. To improve the application's usability, audio instructions were produced and delivered through a pair of speakers. The main reason for using audio instructions was to reduce written instructions, with which dyslexic children would have problems reading them [11, 14]. Effectively, these audio instructions helped reduce dyslexic children's problems during navigation, allowing them to perform the required task or test more effectively. In addition to the speakers as an output device, 
The International Journal of Multimedia \& Its Applications (IJMA) Vol.9, No.4/5/6, December 2017

D-Potensi used a monitor to display the virtual surroundings in which the children could explore interactively.

\subsection{Creating ANd Modeling 3D OBJects}

One of the main challenges in developing VR applications is to create an environment that looks realistic and interesting. To simulate such an environment, related objects must be generated in 3D. In the production of these objects, critical elements, such as size, texture, surface type, and lighting of the object, need to be carefully considered. Hence, in this study involving three simulated virtual environments, all relevant objects identified in the domain phase were designed and modeled accordingly. In this respect, there are several techniques that can be used in creating and modeling 3D objects; however, the technique of modeling polygons is the most widely used technique in game application development [39]. In this technique, a 3D model is generated through a combination of multiple polygon surfaces, and the number of these polygons determines the realism of an object - the more polygons used, the more realistic the object is. However, large numbers of polygons require intensive rendering processes that usually result in long delay in running the application [40]. Thus, developers need to take into account this factor in the creation of $3 \mathrm{D}$ objects.

In a VR application, real-time rendering is required to display all contents of the virtual environment. Typically, the proportionality required for a smooth display without latency for a monoscopic screen is 50 to 60 frames per second. To reduce rendering rates to this level, some optimization techniques can be applied during the 3D modeling process, namely by reducing the polygon size and by using appropriate texture mapping. Such techniques were deemed appropriate to model the 3D objects of D-Potensi application, given that it was implemented on the online platform. Most 3D models of this application were created and edited using several software, such as 3D Max Studio, Crazy Bump, Z-Brusher, and 3D Coat. Additionally, in this sub phase, several possible and impossible figures (for impossible figure task) were created and added to the virtual world, as such figures have been shown to be suitable test items in diagnosing dyslexic children's potential [12, 41, 42]. Alexeev [43] defined an impossible figures as a 2D image that could not exist in a 3D world. Therefore, creating these figures in 3D space entailed the researchers to make several modifications to the normal steps of objects creation. Figure 1 and Figure 2 show the steps of impossible figures creation and an example of an impossible figure, respectively.

\subsection{Creating Terrains}

In the domain model phase, the researcher created three (3) environmental themes, namely Pulau Awan, Taman Cokelat, and Istana Pelangi. These environments were deemed appropriate based on the unique characteristics of dyslexic children, who typically have vivid and creative imagination $[11,14,18,44]$. To engender a sense of immersion, the three environments were created with 3D terrains using Unity software as depicted in Figure 3. 
The International Journal of Multimedia \& Its Applications (IJMA) Vol.9, No.4/5/6, December 2017
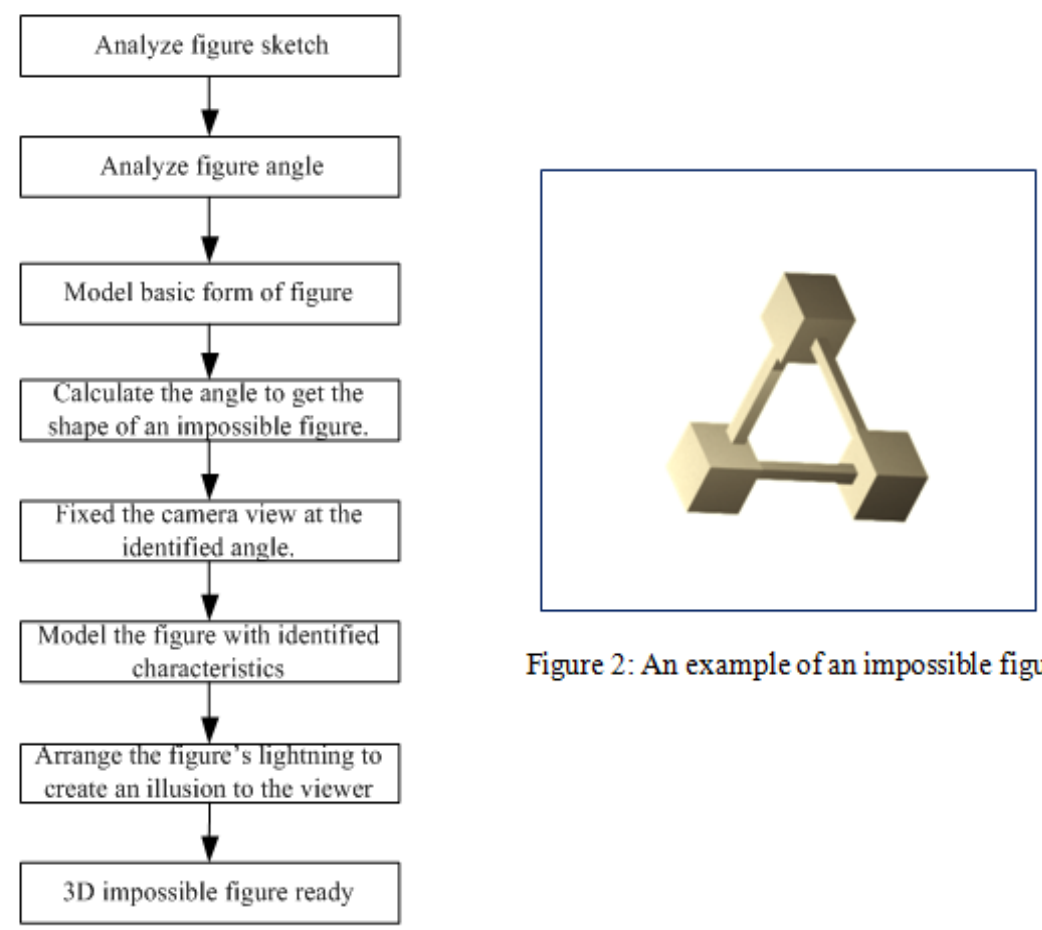

Figure 2: An example of an impossible figure

Figure 1: Impossible figure creation steps

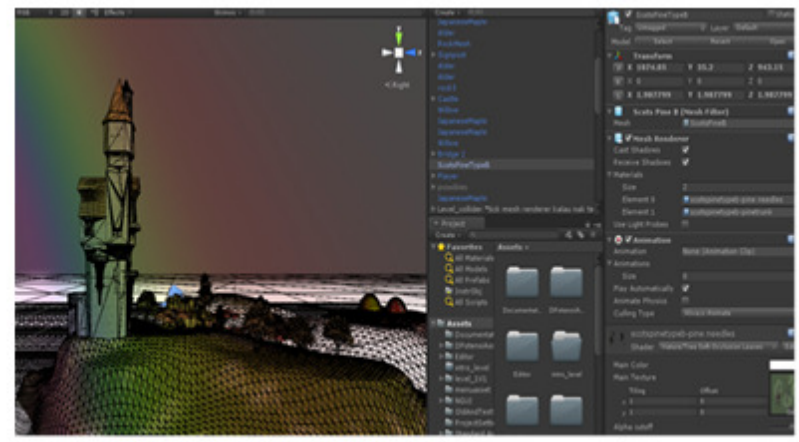

Figure 3. Terrain creation using Unity

The implementation of the D-Potentsi application started with the main menu display before children were allowed to explore the VR environment to perform a given task. The development of this main menu was based on a combination of several website usability and dyslexia usability features. The websites usability features, which were proposed by the U.S. Department of Health and Human Services [45], used for the main menu were a clear headline, meaningful link labeling, use of text for links, and black text on a blank background. For dyslexia usability features, the researchers used beige color and Arial fonts for the background, as suggested by the British Dyslexia Association (BDA) for readability and legibility [29].

The main menu also contained a brief audio instruction to highlight the application's functionalities. Without such audio instruction, dyslexic children would have to rely on text to read the required instructions of the application, which would be problematic as they generally 
The International Journal of Multimedia \& Its Applications (IJMA) Vol.9, No.4/5/6, December 2017

had a reading problem [11, 14]. To attract dyslexic children's attention, the three environments used a screen background image that could be rotated to give different views of the user's location. Figure 4 and Figure 5 show the main menu screen of the D-Potensi application based on the first view and second view of the user's location, respectively.

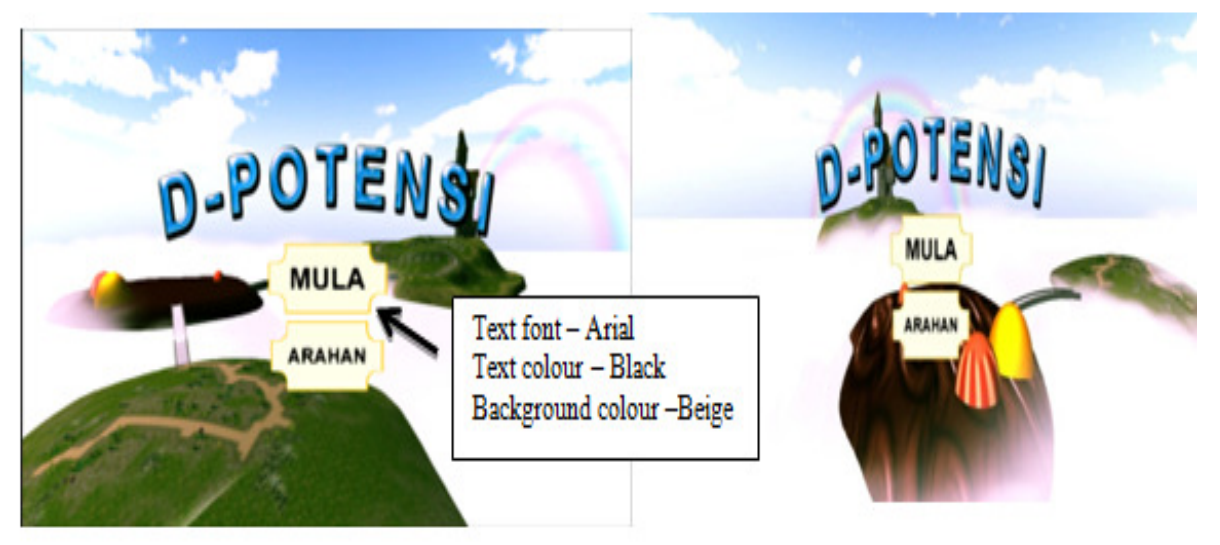

Figure 4. Main menu with first view

Figure 5. Main menu with second view

In addition to the main menu screen, the application has two more screens, with the first showing the required instructions and the second depicting some examples of impossible and possible figures. The first screen consists of key descriptions of how to use the D-Potensi application. The format or design of text on this screen is based on the usability features of websites and dyslexic characteristics. In addition, this screen contains audio instructions to explain the use of each key. Effectively, the audio instructions helped the dyslexic children to follow the instructions without having to read written instructions, with which they would have some difficulties in doing so. The second screen contains some examples of impossible and possible figures to allow the dyslexic children to distinguish between these two types of figures before performing the required tasks. The application provided ample time for the dyslexic children to familiarize with the features of impossible figures such that they would have sufficient knowledge to perform the required tasks.

For the development of the three virtual environments, the researchers used Sutcliffe's [28] goal directed exploration guideline to develop the tasks together with the relevant elements, such as skies, trees, grasses, and flowers. This use of the guideline was carried out in two stages. First, the exploration paths to be navigated by users were identified and constructed in each environment, such as the path shown in Figure 6. Second, 10 questions related to visual-spatial tasks were identified and positioned at strategic locations along this route in each environment. Overall, there were 30 questions strategically located along the three navigation routes in the three environments. Answering the questions helped the dyslexic children to diagnose their VS potential. To help the children to view such locations of the questions with ease, the researchers placed a flagpole at each location. 
The International Journal of Multimedia \& Its Applications (IJMA) Vol.9, No.4/5/6, December 2017

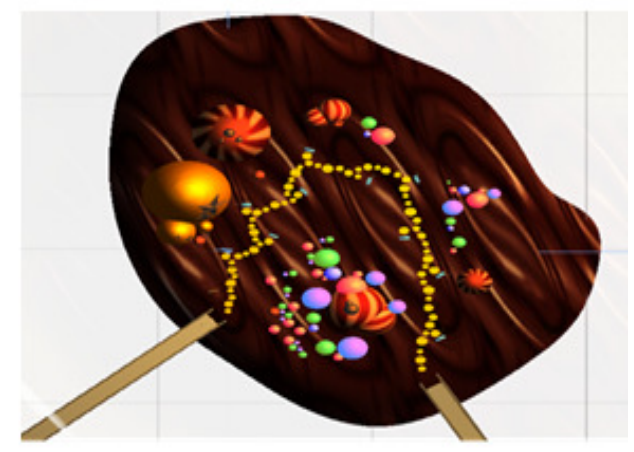

Figure 6. A bird view of the exploration path

To make the dyslexic children captivated by the tasks, each environment uses different design concepts. For example, a stump is used in the Pulau Awan environment. Meanwhile, a lollypop and a hut are used in the Taman Cokelat and Istana Pelangi environments, respectively. In order to perform the required tasks, the children were required to stop at each location to answer a given question related to a given figure. To do this, they needed to view the figure carefully and then press ' $\mathrm{Y}$ ' for a possible figure or ' $\mathrm{T}$ ' for an impossible figure. The letters ' $\mathrm{Y}$ ' and ' $\mathrm{T}$ ' stand for 'Ya' (meaning 'Yes') and 'Tidak' (meaning 'No'), respectively. Each child was given only one chance to answer each question. Figure 7 shows three flagpoles highlighting three different objects in the three environments.
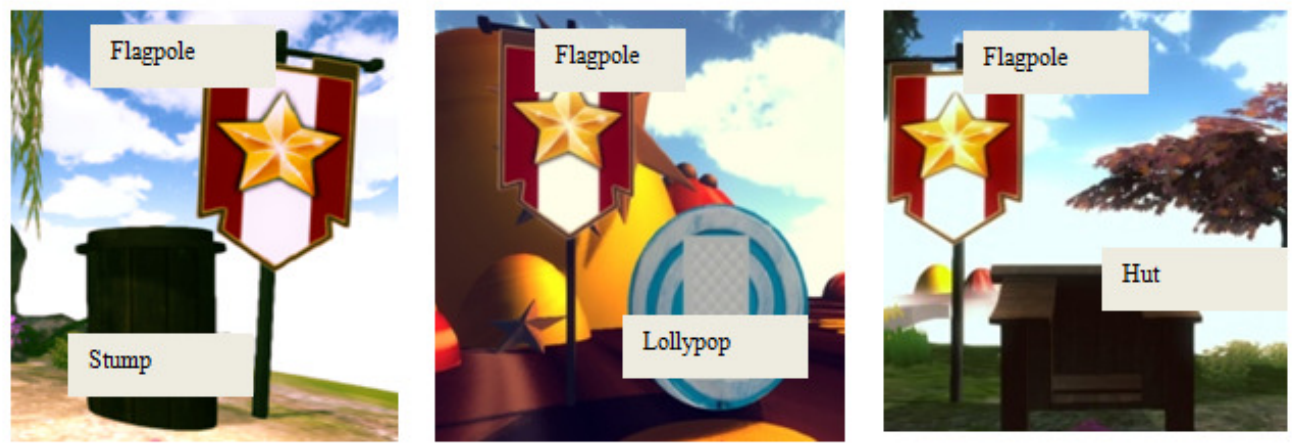

Figure 7. Three flagpoles highlighting three different objects in the three environments

The next elements considered and modeled in the virtual environment were the physical attributes of the objects, such as object movement, speed, and gravity, to which they must adhere to ensure they would not only look real but also behave realistically according to the physical law. In this respect, Sutcliffe [28] contends that the compliance levels of the physical law can be changed to suit the application's objectives. In D-Potentsi, the researchers took into account these factors by applying the law of physics at an appropriate level during the development of objects and terrains of the environments. To prevent users from moving through objects, such as trees or stones, a collider was applied to each object. In addition, several colliders were placed around the island to prevent users from falling off the virtual edges as shown in Figure 8. 
The International Journal of Multimedia \& Its Applications (IJMA) Vol.9, No.4/5/6, December 2017

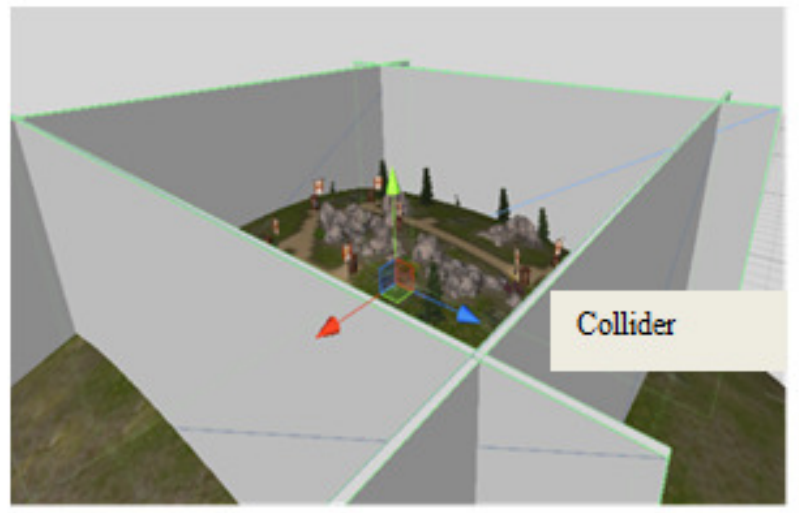

Figure 8. A collider around the island

\section{Diagnostic Testing}

The main aim of D-Potensi diagnostic testing was to identify potential problems in the application such that improvements could be carried out prior to its implementation. Qualitative methods based on the observation technique and a semi-structured interview were used to collect relevant data.

\subsection{Material and Methods}

\subsubsection{Participants}

Eight (8) participants consisting of five (5) dyslexic children and three (3) adults were selected through a purposeful sampling technique. According to Johnson and Christense [46], this technique is suitable for research that involves a population that has unique characteristics such as those of the dyslexia children. In addition to testing the relevant children, the three adults (comprising the president of the Malaysian Dyslexia Association, a teacher, and a father) were selected because they had extensive and direct experience in dealing with dyslexic children. The MDA president and dyslexic teacher had more than 20 years and 10 years of working experience, respectively; the parent of one of the children had eight years of experience in managing his dyslexic child. Table 1 summarizes the demographics of the participants.

Table 1: Participants' demographics

\begin{tabular}{|c|c|c|c|c|}
\hline Participant & Pseudo Name & Gender & Age & Designation \\
\hline D1 & Maslina & F & 64 & MDA President \\
\hline D2 & Fazlina & F & 47 & Teacher \\
\hline D3 & Shahriman & M & 48 & Father \\
\hline K1 & Aina & F & 10 & Child \\
\hline K2 & Adam & M & 10 & Child \\
\hline K3 & Izhwan & M & 12 & Child \\
\hline K4 & Farid & M & 11 & Child \\
\hline K5 & Sarah & F & 12 & Child \\
\hline
\end{tabular}

\subsubsection{Instrument}


The instrument used for the diagnostic testing consists of a series of observation questions, which were adapted from Sutcliffe's [28] goal-directed exploration guideline for children and adult participants. With the adapted instrument, the participants were asked to comment on the application based on their experience in dealing with dyslexic children with unique characteristics.

\subsubsection{Procedure}

The diagnostic testing was conducted at two different locations, t the Ampang Dyslexia Center and the MaiKidz Learning Center, Ampang. The interviews and observations were carried out according to the Johnson and Christense's [46] guidelines consisting of two phases.

\section{Phase 1}

This phase was carried out by first providing the children with a brief description of the D-Potensi and the tasks that they were required to perform. Subsequently, they were allowed to use DPotensi to perform the given tasks, the activities of which were recorded accordingly. The researchers were also present throughout the testing session to help some of the children who were in need of some assistance.

\section{Phase 2}

In the second phase, the adult participants were briefed about D-Potensi before allowing them to use and explore the application. As they were exploring the functionalities of the application, the researchers prompted the participants to comment on the application with regard to its usability for dyslexic children.

\subsubsection{Results and Discussion}

From the observations, all the children were observed to extremely excited in exploring the environments and performing the given tasks. Such excitement was evident as they eagerly navigated to the next location after answering a question at a previous location. As previously mentioned, using the D-Potensi application would entail the children to use the main menu to start an audio file that briefly describes the main purpose and the steps of the VR game. However, all the children were observed to only remember a small part of the audio descriptions, seemingly making them uncertain in what they were supposed do. For example, when asked about what they were required to do in the game, most of them only gave a vague reply such as "I'm going to Istana Pelangi, looking for a treasure". Obviously, they had forgotten the most important part of the descriptions of the game. Arguably, such a problem was attributed to their poor working memory - a common trait among dyslexic children - thus disenabling them to remember the sequence of instructions [47-49]. As for the second part of the audio instruction (that prompted the children to answer a particular question at a specific location), all of them managed to listen to the complete instruction before attempting to answer the question. Such action occurred as the figure related to the question only appeared after the audio instruction was completely delivered.

For the exploration of the environment and the performance of the task, four (4) out of five (5) dyslexic children were observed did not know their location in the environment. In addition, they were noticed to be always disoriented, as the rapid movement or rotation of the mouse in $360^{\circ}$ might have induced such a feeling. Despite such discomfort, they could easily explore the virtual environments by using the arrow keys to navigate to the answer locations by following the paths to the respective flagpoles. However, only two (2) dyslexic children seemed to lack the skills in 
The International Journal of Multimedia \& Its Applications (IJMA) Vol.9, No.4/5/6, December 2017

using the mouse for such navigation, because they constantly required some assistance from the researchers compared to the rest of the children. As such, this particular finding suggests that the paths and flagpoles created based on Sutcliffe's [28] goal-directed exploration guidelines can serve as spatial cues to guide inexperienced users, especially dyslexic children with poor navigation skills, to effectively explore and seek figures in the virtual world. In contrast, skilful dyslexic children were noticed to be excessively overexcited, making them less attentive to the given tasks, with a few bypassing the answer locations that effectively prevented them from answering the questions at such locations. Table 2 summarizes the results of observation on the five (5) dyslexic children during the exploration in virtual world.

Furthermore, the three (3) adult participants stated that the three environments (i.e., Pulau Awan, Taman Cokelat, and Istana Pelangi) were very appealing and interesting, thus reinforcing the appropriate use of such environments for dyslexic children. In fact, they agreed that the virtual paths were clearly visible, the locations at which questions were asked and answered were strategically placed, and the keys for answering questions were appropriate. However, they were quite concerned with some issues that might adversely affect the performance of the VR application. For example, the first participant commented that the audio description of the menu was too long for the dyslexic children to listen to. This comment is consistent with the above finding that shows most children only listened to the last sentence. Hence, she suggested that the duration of audio instruction be shortened. Furthermore, she suggested that the volume of the background music had to be lowered to ensure dyslexic children would not be distracted when answering the questions.

Table 2. Observation data of dyslexic children's exploration and performance in the virtual environments

\begin{tabular}{|c|c|c|c|c|c|}
\hline Participant & $\begin{array}{l}\text { Remembering } \\
\text { the task goal }\end{array}$ & $\begin{array}{l}\text { Exploring the environment to } \\
\text { perform task }\end{array}$ & $\begin{array}{l}\text { Having the ability o } \\
\text { determine the path } \\
\text { to a target }\end{array}$ & Answering question & Things needing attention \\
\hline K1 & Yes & $\begin{array}{l}\text { - Able to use the arrow keys but } \\
\text { not the mouse. } \\
\text { - Did not know how to move } \\
\text { when hitting a collider } \\
\text { - Did not know her location in } \\
\text { the environment }\end{array}$ & $\begin{array}{l}\text { - Sometimes ahe did } \\
\text { not follow the } \\
\text { path, and she } \\
\text { neaded some } \\
\text { guidance. } \\
\text { - Did not stand still } \\
\text { at the answer } \\
\text { locations. }\end{array}$ & $\begin{array}{l}\text { - Able to identify the answer } \\
\text { locations by following the flag } \\
\text { poles. } \\
\text { - Did not have problem in } \\
\text { pressing the answer keys. } \\
\text { - Could differentiate impossible } \\
\text { and possible figures. }\end{array}$ & $\begin{array}{l}\text { - Only liatened to a small part of } \\
\text { descriptions. } \\
\text { - Position at the answer location was } \\
\text { insppropriate to view the figure. } \\
\text { - Lacked the skill in using the mouse. } \\
\text { - Did not follow the identified path. } \\
\text { - Did not know her location in the } \\
\text { environment. }\end{array}$ \\
\hline K2 & Less & $\begin{array}{l}\text { - Explored using 'W', 'A', 'S' } \\
\text { and 'D' keys. } \\
\text { - Bypassad the answer locations } \\
\text { because he explored the } \\
\text { environment too fast } \\
\text { - Knew his location in the } \\
\text { environment }\end{array}$ & - Yes. & $\begin{array}{l}\text { - Able to identify the answer } \\
\text { locations by following the } \\
\text { flagpoles. } \\
\text { - Had no problem in pressing the } \\
\text { answer keys, but he was quite } \\
\text { impulsive. } \\
\text { - Could not differentiate } \\
\text { impossible and possible figures }\end{array}$ & $\begin{array}{l}\text { - Did not listen to descriptions or } \\
\text { instructions } \\
\text { - Explored too quickly and did not pay } \\
\text { attention while answering questions. } \\
\text { - Could not differentiate impossible } \\
\text { and possible figures }\end{array}$ \\
\hline$\overline{\mathrm{K} 3}$ & Yes & $\begin{array}{l}\text { - Able to explore using arrow } \\
\text { keys } \\
\text { - Explored too fast. } \\
\text { - Did not know his location in the } \\
\text { environment. }\end{array}$ & - Yes & $\begin{array}{l}\text { - Able to identify the answer } \\
\text { locations by following the } \\
\text { flagpoles. } \\
\text { - Had no problem in pressing the } \\
\text { answer keys, but he was very } \\
\text { impulsive. } \\
\text { - Could not differentiate } \\
\text { impossible and possible figures }\end{array}$ & $\begin{array}{l}\text { - Only listened to a small part of } \\
\text { descriptions. } \\
\text { - Explored too quickly and did not pay } \\
\text { attention while answering questions. } \\
\text { - Could not differentiate impossible and } \\
\text { possible figures. } \\
\text { - Did not lnow his location in the } \\
\text { environment. }\end{array}$ \\
\hline$\overline{\mathrm{K} 4}$ & Yes. & $\begin{array}{l}\text { - Could explore easily using the } \\
\text { arrow keys. } \\
\text { - Did not know his location in } \\
\text { the environment. }\end{array}$ & $\begin{array}{l}\text { - Sometimes he did } \\
\text { not follow the } \\
\text { identified paths }\end{array}$ & $\begin{array}{l}\text { - Able to identify the answer } \\
\text { locations by following the } \\
\text { flagpoles. } \\
\text { - Did not had problem in pressing } \\
\text { the answer keys. } \\
\text { - Could briefly explain the } \\
\text { possible and impossible figures. }\end{array}$ & $\begin{array}{l}\text { - Only listened to a small part of } \\
\text { descriptions. } \\
\text { - Explored too quickly and did not pay } \\
\text { attention while answering questions. } \\
\text { - Lavel of understanding of the } \\
\text { impossible and possible figures was } \\
\text { low. } \\
\text { - Did not lnow his location in the } \\
\text { environment }\end{array}$ \\
\hline K5 & Yes & $\begin{array}{l}\text { - Had some difficulties in.. } \\
\text { exploging the environment. } \\
\text { - Needed some guidance. } \\
\text { - Did not lnow her location in } \\
\text { the environment. }\end{array}$ & $\begin{array}{l}\text { - Able to see the } \\
\text { path, but lacked } \\
\text { the navigation } \\
\text { skills. }\end{array}$ & $\begin{array}{l}\text { - Able to identify the answer } \\
\text { locations by following the } \\
\text { flagpoles. } \\
\text { - Did not have problem in } \\
\text { pressing the answer kays. } \\
\text { - Could not differentiate } \\
\text { impossible and possible figures }\end{array}$ & $\begin{array}{l}\text { - Only listened to a small part of } \\
\text { descriptions. } \\
\text { - Lacked the skills in using the } \\
\text { computer. } \\
\text { - Did not know her location in the } \\
\text { environment. }\end{array}$ \\
\hline
\end{tabular}


The International Journal of Multimedia \& Its Applications (IJMA) Vol.9, No.4/5/6, December 2017

On the other hand, the second adult participant commented that the D-Potensi application did not have the extrinsic motivational element that otherwise would have provided positive reinforcement for the dyslexic children when they had given a correct answer. According to her, the star symbol that appeared on the screen every time the children got the correct answer was not impactful enough to reward them. She suggested that sound elements could be added to attract children attention. In addition, she recommended that more explanations and examples were needed to help children to understand the concept of impossible and possible figures. Likewise, the third adult participant also highlighted the need to include a more forceful motivational element in the VR application. He even suggested that firecrackers animation should be included to greet and acknowledge children' successful attempt in a particular task, such that they would be motivated to continue exploring the virtual environments until all the prescribed tasks were completed.

Based on the results of the diagnostic test, the researchers propose a number of suggestions to improve the usability of D-Potensi as follows:

i. An audio describing the application's functionalities and usage instructions should be brief or concise.

ii. A tutorial video should be included in the menu section to explain the characteristics of impossible and possible figures.

iii. A collider should be placed at every answer location to prevent users who have not answered a given question from going to the next location.

iv. A collider should be placed around users as they reach a particular answer location to prevent them from moving away until they have answered a given question.

v. Any unanswered questions should be clearly and visually highlighted or flagged.

vi. More creative and interesting features, such as animation of stars, should be included to highlight and acknowledge users' correct answers.

vii. Firecracker animation should be added to highlight users' successful attempts at the various levels of the game.

viii. An arrow symbol for the first control agent should be embedded to show a user's position in the virtual environment to help him or her explores and perform a task.

ix. A mini map should be placed at the upper corner of the screen to indicate a user's position in the environment.

x. The orientation of the user's view should be limited to only $180^{\circ}$ to minimize the effect of disorientation.

xi. The interface should be redesigned to make it more structured or organized.

\section{Conclusion}

In this paper, the researchers discuss four (4) main activities in designing the virtual environment for diagnosing dyslexic children's potential, namely the determination of VR types, selection of modalities and interaction devices, creation and modeling of 3D objects, and creation of terrains. The determination of the VR type was governed by several practical, safety factors, namely affordability, ease of use, and accessibility. The choice of modalities and interaction devices was based on the ability and knowledge of dyslexic children. For the creation of 3D objects and 
The International Journal of Multimedia \& Its Applications (IJMA) Vol.9, No.4/5/6, December 2017

terrains, the unique characteristic of dyslexic children and goal-directed exploration guideline were respectively examined and used. Although the design of D-Potensi virtual environment mainly focuses on two main features, namely dyslexic children's characteristics and Sutcliffe [28] goal-directed exploration principles, the findings of diagnostic test shows that these two elements are not sufficient to make the application more impactful. In fact, more elements are needed, such as orientation, position, and movement of the user in the virtual environment. As such, the researchers propose a number of suggestions to improve the usability of D-Potensi.

\section{ACKNOWLEDGEMENTS}

This research was funded by the Skim Latihan Akademik IPTA (SLAI) scholarship of the Malaysia's Ministry of Education.

\section{REFERENCES}

[1] B. Sanou, "ICT Facts and figures 2016," 2016. [Online]. Available: http://www.itu.int/en/ITU. [Accessed: 14-Jan-2017].

[2] B. E. Mennecke et al., "Second life and other virtual worlds : A Roadmap for research," Commun. Assoc. Inf. Syst. CAIS, vol. 22, no. March 2008, 371-388, 2008.

[3] S. Chang and A. Gupta, "I-Sphere: A Virtual Reality Based 3D Interactive Web Navigation Interface," in APCHI '13 Proceedings of the 11th Asia Pacific Conference on Computer Human Interaction, 2013, 334-343.

[4] Gopalakrishnakone, P., Jianfeng, L., Sun, G. P., Abeykoon, A., Noel, O., Fernando, O. N. N., \& Cheok, A. D. (2011). "A multimodal virtual anatomy learning tool for medical education".National University of Singapore, Singapore. Accessed from https://www.researchgate.net.

[5] H.Jacinto, R. Kechichian, M. Desvignes, R. Prost, and S. Valette, (2012). "A Web Interface for 3D Visualization and Interactive Segmentation of Medical Images Data File server," in 17th International Conference on 3D Web Technology (Web 3D), 51-58.

[6] M.Jiang, L. Ma, and X. Qu, (2011). "The design and Implementation of virtual visiting for digital museum based on web," in International Conference, ICAIC 2011, 224, 297-303.

[7] J.-M. Koivisto, H. Niemi, J. Multisilta, and E. Eriksson, (2015) "Nursing students' experiential learning processes using an online 3D simulation game," Educ. Inf. Technol., 22, 1, 383-398,.

[8] M.Blakemore, (2013). "UNESCO global report: Opening new avenues for empowerment. ICTs to access information and knowledge for persons with disabilities," Paris.

[9] M.G.Friedman and D. N. Bryen, (2007). "Web accessibility design recommendations for people with cognitive disabilities," Technol. Disabil., 19, 205-212,.

[10] L.C. Moats and K. E. Dakin, (2017). "Dsylexia basics,".

[11] B.L. Eide and F. F. Eide, (2011). "The dyslexic advanatge: Unlocking the hidden potential of the dyslexic brain," 1st ed. New York, USA: Pearson,USA.

[12] T. G. West, (2003). "' Secret of the super successful . . They' re dyslexic ,"' Thalamus, J. Int. Acad. Res. Learn. Disabil., 21, 1, 48-52.

[13] T. G. West, (2005) "The gifts of dyslexia: Talents among dyslexics and their families," HK J Paediatr (New Ser., 10, 2, 153-158.

[14] R. D. Davis and E. M. Braun, (2010). "The gift of dyslexia: Why some of the smartest people can't read and how they can learn: Updated, 2nd ed. Penguin Group, New York, USA,. 
The International Journal of Multimedia \& Its Applications (IJMA) Vol.9, No.4/5/6, December 2017

[15] T. Armstrong, (2012). "First, discover their strengths," Educ. Leadersh., 70, 2, 10-16,

[16] J. Munro, (2002). "Gifted learning disabled students," Aust. J. Learn. Disabil., 7, 2, 20-30, 2002.

[17] C. Von Karolyi, E. Winner, W. Gray, and G. F. Sherman, (2003). "Dyslexia linked to talent: Global visual-spatial ability," Brain Lang., 85, 3, 427-431.

[18] H. Jamilah, N. U. Hasbiah, K. A. Samsudin, A. Saad, and B. O. K. Saira, (2014)."Requirement analysis for the development of a directed exploration virtual reality potentials diagnosis system for dyslexic children," Aust. J. Basic Appl. Sci., 8, 23, 44-52.

[19] A. M. Bacon and S. Bennett, (2013). "Dyslexia in higher education: The decision to study art," Eur. J. Spec. Needs Educ.,. 28, 1, 19-32.

[20] C. Collinson and C. Penketh, (2010). "'Sit in the corner and don't eat the crayons': postgraduates with dyslexia and the dominant 'lexic' discourse," Disabil. Soc., 25, 1, 7-19.

[21] D. Lubinski, (2010). "Spatial ability and STEM: A sleeping giant for talent identification and development," Pers. Individ. Dif., 49, 4, 344-351.

[22] F. Gagne, (2009). "Talent development through the differentiated model of giftness," in The Routledge International Companion to Gifted Education, 1st ed., T. Balchin, B. Hymer, and D. J. Mattews, Eds. Abingdon, Oxon, 32-41.

[23]C. A. Cohen and M. Hegarty, (2012)."Inferring cross sections of 3D objects: A new spatial thinking test," Learn. Individ. Differ., 22, 6, 868-874.

[24] N. Hartman, P. Connolly, J. W. Gilger, G. R. Bertoline, and J. Heisler, (2006). "Virtual reality-based spatial skills assessment and its role in computer graphics education," in ACM SIGGRAPH 2006.

[25] D. Mestre and J.-L. Vercher, "Interaction between virtual reality and behavioural sciences," in Virtual Reality: Concepts And Technologies, 1st ed., P. Fuchs, G. Moreau, and P. Guitton, Eds. London: CRC Press, Taylor \& Francis Group, 2011, pp. 81-91.

[26] A. Al-wabil, P. Zaphiris, and S. Wilson, "Web navigation for individuals with dyslexia: An exploratory study," in International Conference on Universal Access in Human-Computer Interaction UAHCI 2007: Universal Acess in Human Computer Interaction. Coping with Diversity, 2007.

[27] J. E. Mccarthy and Æ. S. J. Swierenga, (2009). "What we know about dyslexia and web accessibility: A research review," Univ Access Inf Soc, 147-152.

[28] A. Sutcliffe, (2012). "Multimedia and virtual reality: Designing multisensory user interfaces," 2nd ed. New York,USA: Routledge, Taylor \& Francis Group, New York.

[29] I. Smythe and E. Draffan, (2005). "Supporting the dyslexic student at university - A case study of the University of Edinburgh, Scotland." (I. Smythe, Ed.)Provision and Use of Information Technology with Dyslexic Students in University in Europe.wales, UK: Europen Union.

[30] H. Jamilah, U. Nor Hasbiah, and A. Saad, (2014). "Aplikasi realiti maya desktop bukan immersif: Teknologi terkini dalam domain pendidikan,” JICTIE, 1, 1, 2014.

[31] F. Gosselin and C. Andriot, (2011)."Hardware devices of forceback feedback interfaces," in Virtual Reality: Concepts And Technologies, 1st ed., P. Fuchs, G. Moreau, and P. Guitton, Eds. London: CRC Press, Taylor \& Francis Group, 137-179.

[32] S. Coquillart, P. Fuchs, J. Grosjean, and M. Hachet, (2011)."Interaction technique for virtual behavioural primitives," in Virtual Reality: Concepts And Technologies, 1st ed., P. Fuchs, G. Moreau, and P. Guitton, Eds. London: CRC Press, Taylor \& Francis Group, 247-291. 
The International Journal of Multimedia \& Its Applications (IJMA) Vol.9, No.4/5/6, December 2017

[33] L. Reis, E. Duarte, and F. Rebelo, (2013)."Main usability issues in using virtual environments," 189198.

[34] S. Smith and Æ. E. Ericson, (2013). "Using immersive game-based virtual reality to teach fire-safety skills to children," Virtual Real., 13, 87-99.

[35] R. H. Y. So, K. P. Wong, S. L. Yuen, J. Tang, H. Yeung, and J. Liu, (2011)."Virtual reality gaming for rehabilitation: An evaluation study with physio-and occupational therapists," VRCAI, ACM, 1, $212,503-506$.

[36] L. J. Ausburn, J. Martens, A. Washington, and D. Steele, (2009). "A Cross-case analysis of gender issues in desktop virtual reality learning environments," J. Ind. Teach. Educ., 46, 3, 51-89.

[37] J. Polcar and P. Horejsi, (2015). "Knowledge acquisition and cyber sickness: A comparison of VR devices in virtual tours," MM Sci. J., 2015, 2, 613-616.

[38] M. Bruce and H. Regenbrecht, (2009). "A Virtual reality claustrophobia therapy system Implementation and test," in IEEE Virtual Reality 2009, 179-182.

[39] S. Rabin,(2010). "Introduction to game development," 2nd ed. Boston,USA: Course Technology.

[40] P. de Byl, (2012). "Holistic Game Development," 1st ed. USA: Elsevier Inc..

[41] D. W. Chan, (2009). "Developing the impossible figures task to assess visual-spatial talents among Chinese Students: A Rasch measurement model analysis," Gift. Child Q., 54, 1, 59-71.

[42] C. Von Karolyi, (2001). "Visual-spatial strength in dyslexia: Rapid discrimination of impossible figures," J. Learn. Disabil., 34.

[43] V.Alexeev,(2013).“Impossible Figure,”.[Online].Available: http://impossible.info/english/articles/impossible-figure/.[Accessed: 03-Jan-2014].

[44] C. Marazzi, (2011). "Dyslexia and the economy," Angelaki J. Theor. Humanit., 16, 13, 19-32.

[45] M. O. Leavitt,(2003)."Research-based web design \& usability guidelines.", Washington DC: U.S. Department of Health and Human Services (HHS).

[46] B. Johnson and L. Christense, (2012). "Education Research: Quantitative, qualitative, and mixed approaches," 4th ed. California,USA: SAGE Publications,Inc.

[47] M. Laasonen, V. Virsu, S. Oinonen, M. Sandbacka, A. Salakari, and E. Service, (2012). "Phonological and sensory short-term memory are correlates and both affected in developmental dyslexia," Read Writ, 25, 9, 2247-2273.

[48] T. Zeffiro and G. Eden, (2000). "The neural basis of developmental dyslexia," Ann. Dyslexia, 50, 1$28,2000$.

[49] K. Kalyvioti and T. A. Mikropoulos, (2012). "Memory performance of dyslexic adults in virtual environments," in 4th International Conference on Software Development for Enhancing Accessibilty snd Fighthing Info-exclusion(DSAI 2012), 14, 410-418.

\section{Authors}

Dr. Jamilah Hamid is as a Senior Lecturer in Faculty of Art, Computing and Creative Industry. She holds a Bachelor of Science in Education (Hons.) majoring in Mathematics and Master of Science (Information Technology). She obtained her PhD in Internet and Web Computing from Universiti Pendidikan Sultan Idris, Malaysia She has been teaching in high education institutions since 1991 in several subjects such as Programming, Methodology in Courseware Development, Educational Technology and

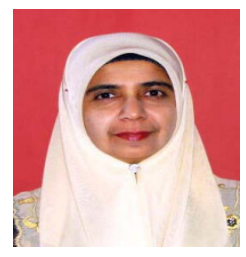


The International Journal of Multimedia \& Its Applications (IJMA) Vol.9, No.4/5/6, December 2017

Teaching Methodology. Her research interests are on Virtual Reality, Educational Technology, Educational Software and Teaching Methodology in Programming. Currently, she is attached to Universiti Pendidikan Sultan Idris and teaching Methodology in Courseware Development.

Dr. Nor Hasbiah Ubaidullah is working as an Associate Professor at Universiti Pendidikan Sultan Idris. She received degree in Computer Science from Universiti Kebangsaan Malaysia and master of Science inInformation System from University of Salford. She obtained her $\mathrm{PhD}$ degree in Information Technology from Universiti Kebangsaan Malaysia. Her research areas include Courseware Engineering, DSS, Learning Disability Children, Systems/ Product Development, Programming C++ and JAVA..

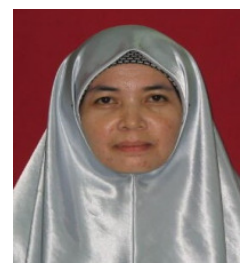

Dr. Aslina Saad is a Senior Lecturer in Faculty of Art, Computing and Creative Industry. She is a graduate in Bachelor of Information Technology (Science and System Management) and Master of Science (Information Technology). She received her PhD in Computer Science (Information Systems) from University of Loughborough and is currently attached to Universiti Pendidikan Sultan Idris. Her research interests are on Computer in Education, Management Information System, Artificial Intelligence and Knowledge Management. Currently, she is teaching system analysis and design and object oriented analysis and design subject.

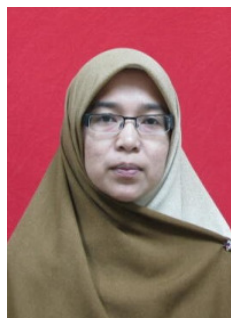

